ALEH DASHKEVICH, VOLHA DASHUK, BEATA DZIANOWICZ, JOLANTA KILIAN, IRYNA VOLAKH, JAN ZAMOJSKI
Images vol. XV/no. 24 Poznań 2014 ISSN 1731-450x

\title{
15 Minutes: Belarus!
}

In 2011 Stowarzyszenie Młodych Twórców - "Ku Teatrowi” - the 'Towards Theatre' Association of Young Artists in Poznan', began the ' 15 minutes: Belarus!' project. Initially this was to embrace only the production of 6 to 8 short documentary films each of 15 minutes. We invited the best documentary filmmakers from Belarus, professional and non-professional directors who for many years had been documenting the work of the democratic opposition in Belarus. The series of such documentaries was to be a type of cinematic précis of contemporary Belarus in terms of the creative documentary. Krzysztof Kopczyński persuaded me to develop this project by including Polish documentary filmmakers. This has borne fruit in a cooperation lasting over several years between Polish and Belarus directors, as well as a battle for every cinematic second capturing the world in the documentaries that arise in the course of our project.

So far there have been two sessions of 'Short Documentary Workshops', (21.10-24.10.2011, The Castle of the Order of St John, Łagów, and 30.11-3.12.2012 in Józefów near Warsaw). Three Belarus short documentaries have also been produced: Almaz by Victor Aśliuk (among others 'Golden Castle' - the first prize at the 17th Off Cinema International Documentary Film Festival in Poznań, Poland, and the first prize from the Story Factory 'For simplicity and beauty of

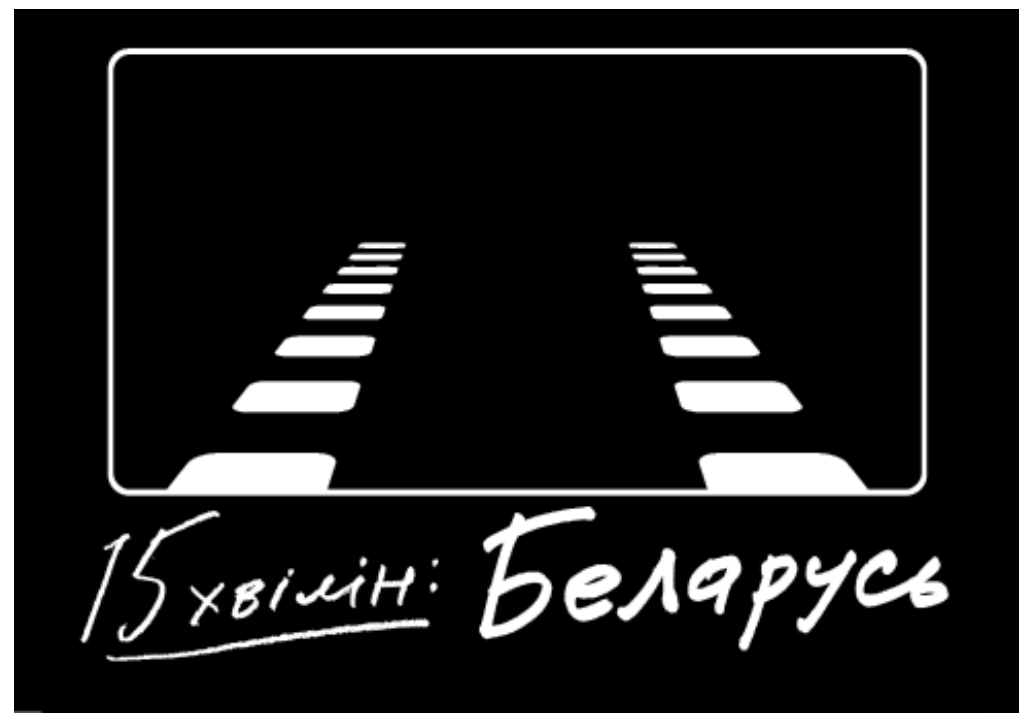

A few words about the project 
storytelling image, sound and silence' at this festival; the Prize for the Best Documentary Film at the Mediawave International Film and Music Festival in Hungary - On The Road), From call to call by Aleh Dashkevich and The Blue Waltz by Iryna Volokh, which are to be screened in 2014 .

In this context we have considered about 20 subjects for films in Belarus. At present, we would like to develop this project so as to embrace Ukraine, where we are receiving increasingly more so-called signals from young directors. Relations between the East and West are becoming recently closer - one more consequence of the project ' 15 minutes: Belarus!' (At this stage of our work it can be clearly seen that the way to a good short documentary is equally complicated and how difficult the ability to share one's experience is - one that is very intimate, emotional, searching and 'singular' for everyone, regardless of differences of culture and generation) This, I'm happy to say, we have managed.

JOLANTA KILIAN

15 Minutes: Belarus! The Long and Winding Road Towards the Short Documentary
Belarusian directors say "the subjects are out there just waiting" in interesting, and at the same time difficult times. Rock songs are "not only about politics but also about love..." says, in turn, a Belarus Rock musician. My close engagement with Belarus cinema for the past three years has borne fruit with the ' 15 Minutes: Belarus!' project, which has produced a series of short Belarusian documentary films. The following Polish documentary filmmakers are already well and truly tied to this project: Maria Zmarz-Koczanowicz, Beata Dzianowicz, Andrzej Titkow and Jan Zamojski (script writer of the animated film Tales from the Kingdom of Lailonia (14 Bajek z Królestwa Lailonii) based on the work of Leszek Kołakowski). Their range of collaboration embraces the review of treatments, synopses, film materials and finally - finding that special work. They are at the same time highly demanding and open to camaraderie as far as the Belarusian film projects are concerne - equally to those that for various reasons have not materialised and those that continue through further stages and begin their life, as it were, together with the audience.

The motto ' 15 Minutes: Belarus!' is not simply a means of counting down time in a film sense, a short documentary formula. The main point is to create a context in which to search for the questions that often appear about heroes, about the opportunities for change, the nature of people, their particular interests and the nature of society. Thanks to Belarusian documentalists, we have had the opportunity to look into the deeper interior of this country, reach the personal history of individuals and their dreams, see scenes that no documentary film maker from the West would have shot. The camera, after all, can record more than our 'passing through'. The discipline of the short film imposes a certain precision in these histories. I asked myself the following question: In the course of fifteen minutes is it possible to tell a story about a single life or someone's dreams? 
Since short literary forms such as poetry or anecdotes are characteristic of Belarusian culture, in fact integral to its customs, then why would they not be a success as a film? Just how much can be said about Belarus in these 15 minutes? This can for example be the so-called university 'quarter' for latecomers to Europe, their university, journey to work or invitation to a meeting... What events have taken place in Minsk during such a 'quarter' between leaving the metro at Praspekt Skaryny and the Academy of Sciences, on a given autumn day? What events might have taken place in the course of 15 minutes on a lane in Minsk, when a certain journalist was returning from the metro station Ploshcha having dropped off a parcel with food for the tent city in December 2010? Fifteen minutes before and after the event. In other words, I waited until my friends show what 5, 10 or 15 minutes of film freedom is.

These were films that could be made beyond censorship and self-censorship - ones that draw on personal observations of the country where you live. These are a documentation of how that particular world impacts on their artistic sensibilities and what stylistic means they are prepared to resort to when grappling with their subject matter. Further, one could ask what measure of humour, the grotesque, or sense of the absurd there is and how much gravitas on the part of the documentalist behind the camera, the careful observer or 'voyeur'? I wondered whether they would manage to capture a significant moment in the frame and what sort of personal histories and events these might be?

Now that the project is at the halfway mark, Victor Aśliuk's film Almaz, as well as three others, are in the final stages of production. In this context one can clearly see the particular issues that could have proved to be an unbearable burden for Belarus filmmakers in undertaking these documentary challenges in using the expressions ' 15 minutes' and 'Belarus'. These appeared as a serious limitation and at this stage the whole project could have failed - but as it turned out this could not have been further from the truth. Belarus is not an easy subject, but for those that live there one of the fundamental challenges. This apparent limitation, however, did not prove to be the essence of the problem that I came across in our mutual work. The whole matter proved to be even more complex as our Belarusian colleagues treated the above mentioned motto literally and, as a consequence, we received various ideas and films on matters that were at times most important for them.

I had the feeling that their particular interest and readiness to take part in this project were the only chance for completing their own films - while for us, those from 'the other side of the mirror' - that is from this side - today's Schengen border - ' 15 minutes: Belarus!' could be the beginning of a long and winding road, as well as an enterprise in abstract thinking. It could also be the documentation of a particular history governed by established rules of building narrational film structure - that for Belarusians represents much more. A project such as this is a locus for undertaking the issues of what being a Belarusian 
means, identity, history, the breaking of human rights and a battle for all of these. Here, all the motley collection of interests emerges - ethnic and social minorities, those on the social margins and 'the crazy ones'. There is no account here of 'the ordinary' and a search of the everyman for a picture of society (or its ills), as was the case in the documentaries of the Polish School.

Moreover, the auteur chooses a protagonist that the audience sympathises with, supports unconditionally, one who it can be seen it understands and treats as a saint. This is a figure that can lead to the discovery of a truth, use it as an allegory or symbol of another world in whom the film maker speaks in a way he would not publically. It can be clearly seen that the Belarusian director goes beyond the bounds of 'western' thinking in respect to documentary film and that his deft, lively stories are created with the audience in mind. Here the auteur searches for particular protagonists and stories (as for example Tarkowski) in whom he himself could play the part of creator - encroaching perhaps even too much into the world of the protagonist and their reality. This needs to be not only a protagonist but a flesh and blood 'hero'. The documentary film is therefore understood by these directors as a utilitarian art form, while the creative process becomes "essential for those that are missing something", as comments one of the unrealised principals of one of the documentary projects that were sent.

Nonetheless, one thing is certain that is available and in common for us all who take part in this project (Belarus in Poland). This is the recognition of the skills of an engaging story in a particular history and making sure that it reaches the audience. Admittedly, each side understands this in a different way for there are different traditions, schools, fairy stories from childhood as well as, of course, the obvious fact that we live in different countries. Here in Poland, we are witness to a democracy in its early phases, which in formal terms has become a part of Europe, as opposed to the other 'side' that is closer to the traditions of the East (with a totally different understanding of democracy and customs). This form of allegory is known to us in Poland from Russian cinema or indeed the Polish Masters. It is between these two traditions that Belarusians are, as it were, suspended. Taking into account the past two decades of alienation from the spirit of Europe, the Belarusian documentary film has to forge its own traditions, just as Belarusian culture in recent years has focused on establishing its own, new myths (tied to the establishment and development of new language forms).

The process of allegory or reference to related symbols is, of course, in this context - one of fear and the challenge of surmounting it, including perhaps self censorship - a particular trait of artists from authoritarian countries. It is at the same time an understanding of allegory in which the power of the image is deeply fixed. It is also necessary to remember the cultural and historical context in which Belarus finds itself and the fact that the 2oth century has witnessed the dynamic growth of cinematography and related production branches in Europe 
to which Belarus practically did not have, and still does not have, access. Not unlike their protagonists, they are in a sense passé, Old School. They are not contemporary and, at the same time, forced to live in the contemporary. In the past 20 years as a result of the enormous effort of artists and the opposition in Belarus, they have managed to preserve their language. It has become a reality in literature, speech, music, the plastic arts, film and in theatre. It could be said that there is too little of it, but it is there. We should make sure that it does not disappear and that we help it grow, just as the languages of its neighbours are growing. These Belarusian histories in the creative context must find their own unique form of communication with the living material of Belarus itself and with the world beyond. This, it would appear, is fundamental and at the same time very important.

Often these documentaries are a mixture of various styles in search of truth and audience appeal'. The issue of the breaking of human rights, for example, is commented on by borrowing the journalistic style of the West, while for other subjects there is a search for 'something akin to' the culture of the West. The means of expression that have been proven among the public in the West, ones that entertain or dramatise histories, when transformed into the Belarusian context enjoy a short life; theatre productions, projects musicals, films or television documentaries, or indeed reaching out to the so-called contemporary arts in the form of various types of installations and gallery structures. These are 'temporary' cultural events, not histories told through art itself - ones that have an opportunity to become significant elements of Belarusian cultural traditions. As far as the tradition of European individualism is concerned, the personal 'account', filtered through its own experience was, and still is, important - no less in documentary film.

It would appear, moreover, that this phenomenon is only just taking place in Belarus. It is accompanied by the ethical dilemmas of directors and artistic decisions such as: whether the work is to be 'the voice of the people', or a personal, private comment; whether this should concern the 'people', society or the individual. Indeed, with what sort of 'voice' can the documentary speak in the country that they themselves admit has a schizophrenic reality? One way or the other, it is with enormous interest that we engage with the stories coming from Belarus. There is increasingly less 'off' in these documentaries, less and less does a director comment on what the audience can see but does not, and the awareness of the camera operator's contribution is increasing and, therefore, so too the power of the image, which so far has been reserved for iconostasis, the great symbols of the past epoch.

If the documentary, even the 15 minute one, as every work of art, is the creation of 'deception' and a charade of leading the audience into a simulated world that the artist subsequently strips of its apparel, demonstrating explicitly its mystification, then Belarusian myths and their protagonists also should be subjected to this particular alchemy. This is all the more so in that in every story constructed, as Aristotle's 
wished in his Poetics, there is room not only for the brutal truth. There is also room for hope. It is this element of the European tradition that is lacking in the creative work of Belarusian documentaries. It is possible of course to argue with this, but there is no way that we can afford not to know or to ignore it. The times of Soviet mythology in Poland are, fortunately, well and truly behind us. No narrative form therefore has to refer to propaganda and it is in this context that the complex world of contemporary Belarus provides new myths and subjects for film. The time is ripe, it can be said, for an immediate deconstruction and for the mystification of old histories, the creation of new worlds, such that the culture takes on a tempo of growth and at the same time preserves the most valuable elements of human values.

Belarusian documentalists who form the living canvas of auteur cinema, those that work with screenwriters, bring to Poland stories of prostitutes, small town loners, the heroic deeds of community activists, war veterans and their love of life, the loneliness of wives of prisoners of conscience, their children searching for happiness abroad, a politician's future, as well as young researchers going from town to town and recording the stories of the last witnesses to partisan wars - and many, many others. These stories, as human stories, are engaging and moving and sometimes are boring. The point is how to spin a story so that it does not become lost in all the hullabaloo of the media, in the daily accounts of tragedies in other parts of the world, in international festivals and, most of all, in Belarus itself? The only answer that makes good sense is simply to tell a story that is worthwhile, honest and powerful, as well as most of all one that is brief. The scripts for great stories and works of literature begin from one sentence.

VOLHA DASHUK

15 Minutes: Belarus! My Workshop
Most of all I like learning. Master-classes and workshops connected with filmmaking are a very desirable activity for me. So I immediately agreed when Ms. Jolanta Kilian suggested I could apply for participation in her initiative “ 15 minutes: Belarus!”. Her project was actually unique. Mostly Polish, but also international experts, educating a group of Belarusian documentary film directors - that sounded new. We had not had something like that in Belarus before.

As a documentary film director, I had already participated in numerous workshops. On the whole, they were intended to help filmmakers prepare their projects for international co-production. Not only had I got new knowledge there, but also could successfully participate in international pitching forums. At the same time, you can never be over-experienced, since every new film means starting anew with new worries about an uneasy task of developing your idea. So some critical guidance of high-level tutors at that moment is always helpful.

Besides, all of us selected for " 15 minutes: Belarus!" were of different professional backgrounds and experience. For some people who 
were at the beginning of their filmmaking career such a workshop was an absolute novelty. Moreover, Belarusian filmdirectors have very restricted possibilities for this kind of studies. To some extent, they exist isolated from international filmmaking communities and events. In addition, as a rule, all educational enterprises like this are expensive and the participants have to pay a tuition fee as well as their accommodation and travel expenses themselves. Taking into account the fact that there is not any Film Institute of Film Fund in Belarus to support emerging talents, it is clear that such an activity becomes unaffordable for the majority of our filmmakers. In contrast, the participation in " 15 minutes: Belarus" was absolutely free and everything was provided for. What is more, the working language of the workshop was Belarusian, an advantage which allowed non-English speaking Belarusian directors to participate.

After all, the format of " 15 minutes: Belarus!" was special as well. Generally, you need to come up with a feature length project to present it for a pitching forum workshop, which is rather challenging in an organizational and financial sense, whereas a short project is easier to start with. So "15 minutes: Belarus!" was a good opportunity indeed.

My expectations from the workshop did not prove correct just in one respect. I did not think the programme would be so intensive. It meant there was no time to relax at all. Lectures, presentations, screenings and individual consultations took up all the time from early morning to late evening. The nights were for homework...

One of the most inspiring things was meeting outstanding people. Polish classical filmdirectors and other experts were our lectures. Nevertheless, it did not mean we had a blissful, tranquil time there. Quite to the contrary, we felt insecure and strained, with our projects under scrupulous review, having been attacked by the tutors who, however, at the same time, effectively mobilized all our professional skills and stimulated resourcefulness.

It all began with the conclusions that Jan Zamojski, a script writer and philosopher from Poznan, was to draw from the descriptions of our projects. He had done a huge amount of work and his critical remarks on each project were much longer than the projects themselves. Andrzej Titkow, a director and poet, was also merciless: "Why do you say it's a unique situation? I myself filmed something like that in Poland. You really need to give serious reasons to prove you're right!" At first, it was really frustrating to realize and accept that your documents on the project and your presentations were susceptible to so much criticism, especially if you already had dealt with such things successfully. Later on, the realization came that if you were be able to answer these questions properly and seriously counter the critical remarks, your project would definitely gain. Gradually in our consciousness the tutors started transforming from our enemies into allies.

Beata Dzianowicz, a director, filmcutter and lecturer, was speaking about editing - showing us films we had no chance to see before. Maria Zmarz-Koczanowicz, a director and lecturer, was also presenting some 
interesting films, her own included, talking about different aspects of documentary filmmaking, for example, an antagonist as the main character. Director and producer Krzysztof Kopczyński was showing how to prepare a documentary project for an international market. It was all summed up in a comprehensive lecture of Danish expert Ove Rishøj Jensen on presentations at international pitching-forums. What was so important about all these lectures was the fact that all the tutors were completely at our disposal, a very favourable situation for the project's development. We could ask questions and get advice in individual consultations.

Of course, all the participants benefited from these studies, which lasted over a period of two years actually. This included two working sessions and individual meetings with masters in between. All this time it was wonderful to know that you were not alone with your project and that someone was interested in your progress and always eager to help.

At the end, the level of all the presentations was much higher. One of my colleagues impressed me so much with his inventiveness. Having a good subject, he, however, was the only one who did not have a pitch-pilot, a disastrous disadvantage. Still, he managed his task brilliantly. In the middle of his presentation, he suddenly started drawing on the blackboard, representing his characters and the conflict among them in such a vivid and humorous way that this visual illustration took over the function of a proper trailer.

The workshop had other unexpected consequences for me personally as well. One of our lectures, who had been speaking about the art of the short film in the tradition of the Polish documentary filmmaking school, was Mikolaj Jazdon, the director of the International Documentary Film Festival “Off Cinema” in Poznań. In 2013 he organized an international conference on documentary cinema in the framework of the festival, in which he invited me to take part. I was glad to participate and prepared a presentation on the topic of modern Belarusian documentary films in the European context.

Finally, after all this work connected with " 15 min: Belarus!" I felt that Polish culture in general had become closer to me and I started learning the Polish language. Now I am reading a famous book by the American theorist Christopher Vogler "Podróż Autora. Struktury mityczne dla scenarzystów i pisarzy" ("The Writer's Journey: Mythic Structure For Writers") not in its original English, which would be more natural, but in its Polish translation and I am very proud of myself. Polish penetrates into my head together with classical dramaturgic postulates, which I hope will help me, if I happen to work on a feature film script.

The Producer is No Big Wolf

JAN ZAMOJSKI

It would appear that Jolanta Kilian, the spiritus movens of the "15 Minutes: Belarus!" project, proposed that I take part for two reasons. First, I happen to work as a script writer mainly for animated film and am subject to very high demands that are specific for this genre on the 
part of the producer and director in regard to, foremost, the crispness of the script and its record, as well as the correct understanding of subsequent stages of the conceptual path as far as the film is concerned. The last has enormous significance, for the submitted film projects have to contain not only a finished script but also a treatment, or a condensed presentation of the script. Secondly, I knew literally nothing about Belarusian documentary film and was therefore free of any particular position, be it sympathy, or antipathy, even if I was unconscious of this fact. For my part in turn, work on this project meant rubbing shoulders with a completely new canvas of cinema - one that intrigued me to a huge extent. In this context I ought to add that my taking part afforded me the opportunity to verify various stereotypes that I had become subject to, as far as independent Belarusian directors and their films were concerned.

Thus at the very beginning of the project I received 13 submissions for assessment that apart from information on the authors (these I not read on principle) contained (at least they ought to) a short abstract of the film, synopsis, treatment and director's statement. I went on to analyse them from the point of view of the potential audience that simply wishes a film to be made on the basis of a given project. Thus it is essential that the project is convincing for a future producer and that both the producer and potential audience want this production to be a success. I also assumed that the writer of the project, as a result of the information given, wishes to produce the closest representation of the proposed film in the imagination of a potential producer and that therefore my role is to make those submitting project proposals aware of any deficiencies in this respect.

In addition, an awareness of the project's importance of the formal and external or aesthetic aspect for the reader is required as this testifies (or not) to the professionalism of the film maker. In this respect I was concerned with sharing my experience of the importance of the conceptual stage of the film. This relates to communicating the main ideas, the fact that assessment of the project is only possible on the basis of reading the proposal and therefore projects such as this ought to be carefully thought out and executed, as well as being communicative. This, it turned out, was no simple matter.

The synopsis, treatment and director's statement are not only the successive stages of the project and at the same time integral documents when they are presented to the producer, but also serve to organise the collected material (in the categories of film dramaturgy) and therefore play a role in structuring the film maker's concepts. The deficiencies that occur in most of the projects are a lack of familiarity with the above subjects and their concepts, which results not only in their misuse but also so-called contamination. As a result, the majority of projects were submitted as a consolidated text under the common heading of "Synopsis, Treatment and Director's Statement". This meant that the submission was burdened with an overly literary character (the 
most often used means of covering treatment deficiencies) or too much detail (the most frequent way of covering up a lack of ideas). Naturally, some projects that were very interesting were deficient here, which gave the impression that a spectre of scepticism hovers over the majority of propositions in regard to their potential.

Consequently in all the opinions that were given in writing, the following comments were made in respect to the synopsis, treatment or the director's statement:

Depending on the professional and the so-called film narrative dramaturgy that is to be the basis of the film project, the above concepts may have a larger or smaller importance, which nevertheless differs to the extent that they cannot be applied interchangeably. Usually the synopsis is understood as a short, half-page project description in terms of plot, while the director's statement contains three or four elements such as 1) the proposed film concept, 2) a paragraph on the main protagonists and episodes of action that emphasise the main conflict serving as an engine and its originality, 3) a paragraph on the setting, and 4) possibly one relating to inspirations arising out of the documentation (obligatory in a documentary). The treatment is written in the present tense and its basic unit as it were, is a sequence (set of scenes) without dialogues (should they play an important role, they can be summarised as a description) and information on a character's internal life. This should all be written so that the sentences already correspond to situations that occur in our imagination when we imagine a film that is yet to be made. The treatment plays an enormously important role: it allows the reader to see where the plot bogs down, places where there is a tendency for verbosity as well as to see literary flourishes when there is a lack of ideas - for example the picture given of a character's psychological state.

In the case of only one project did the above not have the following continuation:

All the elements of the conceptual stage of the film have two tasks: to make the film maker aware of any deficiencies in his proposal and to animate the imagination of the reader (producer) through a set of images as close as possible to that planned by the film maker and attractive enough so that the producer wishes to support the project.

The producer is not an opponent who should be charmed by literary means of expression - the producer is an ally, thanks to whom it is possible to make a film that is closest to our intentions. That is why from the very beginning the producer deserves to have complete knowledge of the film maker's intentions.

This was also the theme of my short lecture at the workshop in Łagów which is also the title of this text - there is no need to be afraid of the producer when expectations are fulfilled in regard to the conceptual stage of work on the film.

At this moment of our emerging relationship, participants in the " 15 minutes: Belarus!" project, if they so wished, could easily say I'm a typical teacher. However, I was given much more, something significantly more important than the corrected submissions. They 
realised that I was being frank with them and in return gave me their trust. The majority signed up for individual tutorials. There is no need therefore to add that as a scriptwriter in the company of renowned and recognised Polish and Belarusian documentary film makers, such a state of affairs means that one definitely feels needed.

There still remains the matter of the actual value of the projects submitted. Each had something interesting and some were potentially outstanding - as for example the film by Viktor Aluk on Oswald, who had spent two years in Minsk before he (?) shot down Kennedy. Other submissions drew one's attention through clear analogies with phenomena taking place in Polish independent culture during communist times and films that documented this period such as Volha Dashuk's film on an alternative theatre functioning in Minsk, or the Svabodny Teatr. My attention was drawn particularly to those proposals in which the element of anxiety was strongly noticeable. This was the case with Iryna Volakh's Train to the West, about which the director (her daughter is a student in Poland) wrote as follows:

Everyone without exception for whom the very nature of being Belarusian is important, is open to the future of Belarus and wishes to act in its name and offer something. Those who have initiative and wish to do their work conscientiously are forced sooner or later to emigrate, so as to later, having experienced the trials and tribulations of migration, search for the road of return.

In turn, in my assessment I wrote that "I understand this full well for in Central and Eastern Europe everyone who now has a grown-up and educated child, has stood on such a platform to say goodbye en route to a better world". Another of these projects, the film by Aliaksandr Matafonau Sadness and Joy, triggered a thought that the film maker, as commented previously “is someone 'in-between' who is preparing to leave the old spiritual home (whose symbols are still highly present in his language) and perhaps has already left it internally, but has not yet reached the new one", and I added:

If it were possible to make such a film, then the history of its maker will personify the spiritual places where at present (I think) the majority of young educated Belarusians are. It is necessary to capture this phenomenon without a protective shield and the past and the future that it strives towards in all its delicacy provides the challenge - who knows - of making the most important documentary film on contemporary Belarus.

In the subsequent stages of the completion of the project I was mainly involved with the role of dramaturgy in the documentary film script, through individual consultations in Poland with participants (I also had a presentation on the subject during a workshop in Józefów), as well as assessing various edited versions of films that were realised in the framework of the " 15 minutes: Belarus!" project. As a result, I discovered a type of film narration that appealed greatly to me and, in return, I was responsible to some extent for the fact that 
Belarusian documentaries became the subject of interest for those engaged in philosophical film. All this, however, deserves a more comprehensive study.

IRYNA VOLAKH

Before joining the project I had made about thirty documentaries as a professional filmdirector. So I had had creative experience already and the project had drawn my attention, first of all, by its ambitious problem statement. To show briefly and expressively just in fifteen minutes the life of the whole country is an uneasy task. Of course, it had to be some aspect, a detail, a person or an episode, the only one, but very characteristic for Belarus right now. That is why I had not chosen my subject straight away.

The most exciting stories are the stories of human fates. Moreover, the human fate is connected with the fate of the country. Eugene Staravojtau is one of very few remaining veterans of the Second World War who had taken part in military operations. Staravojtau had been an orderly and from his Polesye village he had made his long way to Berlin having been wounded three times. He has numerous war decorations. $\mathrm{He}$ is a person of a classical, one might say, of an exemplary Soviet, and later on Belarusian, biography.

However, this is just one and not the most important side of his life. Modern Belarus lacks real tolerance, freedom of opinion and breadth of view on the diverse world. Generally, it is not possible to press a complicated human life into a simple fixed scheme. This discrepancy also characterizes Belarus today. My protagonist is an old man already. Before passing to his eternal rest, he decided to tell me the story of his love, which does not confine itself either to Soviet, or to post-Soviet canons.

Eugene found himself on the front when he was 17, whereas now he is 89 . At 80 , when computerization reached his native Luninyets, a small Belarusian town not far from Pinsk, he learned how to use a computer. He typed his diaries that he had been keeping during the war, in which he had been honestly describing everything he had had occasion to see.

Staravojtau creates self-made books and gives them out to people because he considers the truth about the last war to have been completely falsified by Soviet propaganda. "We were taught to hate the enemy whereas we should have been taught to hate war", he says. He is a convinced pacifist and he can love faithfully and devotedly.

Eugene Staravojtau got to know about his non-traditional orientation already after the war, in the 6os. He was a military interpreter then and once in a library he read a book by psychoanalyst Freud in English. So he understood that homosexual love occurred in nature and, as it turned out, he had loved his childhood friend Nikolaj (Nick) in quite a different way than he had first thought. 
Nick died in 1951 of a grave disease, whereas before there had been many years of friendship, letters from the war, poems and emotional bond. As teenagers the three of them had been friends - Eugene, Nikolaj and Nikolaj's sister Maria. Maria had loved Eugene. It seems she had never married. As it turns out, Eugene had loved Nikolaj and understood this just after his death. This revelation had stunned and overwhelmed Eugene Staravojtau. Even now every year on the day of Nick's death, he brings flowers to his grave. What is more, he has dedicated to his beloved a poem which is called "Blue Waltz". Now Eugene is a very old man. Almost nothing is left - neither health, nor memory, nor friends and relatives, but his love is still alive. With his every step towards eternity these youthful recollections are becoming more vivid, replacing all the rest.

As far as the workshop is concerned, it was important and interesting to me to get to know the way of making films in another country, another way of life and production as well as to take a closer look at the experience of producing movies and working on international co-production projects. After all, I wanted to know better the powerful school of Polish documentary filmmaking. It all was extremely important to me and of great help in the realization of the project.

ALEH DASHKEVICH

This project " 15 minutes: Belarus!" became a good school of professional improvement for me since I had come into documentary filmmaking, one might say, by chance, without a proper academic education. The lack of it I feel up to now. About ten years ago, before I made my first film, I had happened to work as a television reporter and had perceived the process of making a documentary through the glasses of a television journalist, but not a director.

The participation in the project helped me to look at documentary filmmaking in quite a different way. I hope my project "From call to call" is made just in the manner of documentary cinema and not television journalism.

It was not a great deal for me to decide on the subject and protagonist for my film. The problem of human rights is one of the most relevant in Belarus now. Alies Bialiacki, the leader of Belarusian human rights activists, is a symbolic personality for modern Belarus. This man, a kind of Lancelot of our time, is fighting courageously for the freedom of his people against the dragon of authoritarian rule. Besides, I have known him personally for quite a while and his film has become an attempt to support him and his family, which found themselves in such hard circumstances.

The other thing was that it was difficult to define the film's form. How can one represent the subject when the protagonist, being confined in prison, is absent and absolutely inaccessible? 
The idea of showing the fate of Alies through his wife Natasha came not at once but as time went on such an approach seemed more and more appropriate. The story of a woman waiting for her unfairly imprisoned husband, struggling for the happiness of her family while not breaking down under the strokes of misfortune, makes a universal topic understandable for anyone in any country on Earth. Natasha's image has everything a viewer needs - faith, hope and love. The wife of a protagonist has to be just like Natasha is - beautiful, sincere, intelligent, very tired but firm in her endurance. It inspired me a lot that such a variant in the plot's building had been supported by my Polish and Belarusian colleagues.

In general, the working on the subject at the workshop in Poland was very fruitful because besides the help on the development of my project, there was other useful activity as well. When a circle of real professionals gathers, it brings about an interesting creative atmosphere, which, unfortunately, we cannot have in Belarus. What is more, the contact with an excellent school of Polish documentary film, meeting with representatives of the most well-known organizations and production centers of European film industry as well as just private informal talks about modern documentary cinema, provided all participants with a creative positive mood.

The only thing I would recommend to the organizers of the project " 15 minutes: Belarus!" is to select participants with more equal professional experience.

It does make sense to promote and develop the projects like this, especially since at the end a specific product is delivered - a film, which can be shown, discussed and used in future.

Beata DZIANOWicz

\section{A Filtered World}

A beautiful woman is carrying heavy bags. She passes dull streets and enters a building. We look at her and see that something is not right. Either she is too pretty or the bags are too heavy. And definitely not that setting! She would be at home in elegant interiors, glowing sands by the sea or perhaps a lecture hall. Yes! She could be a lecturer, stand at the board and explain to students how it is that in the middle of our galaxy there is a gaping black hole with a mass of several million suns, while we are able every day to rise and exist. She could stroll on her high heels and some of the students, instead of listening to a lecture on cosmic matter, would entertain pleasant thoughts about those legs, her and that unique smile. Oops! The heel is caught in the crack of the parquet... Instead of all this, our breathtaking beauty is lugging heavy bags and enters the building. Before her a pyramid of stairs. Some $50-$ steep, plain and empty. The woman fixes her gold-as-wheat hair. Climbs the stairs. Cut. Inside a post office. A bored postal worker is weighing something. The woman's parcel is too heavy. She takes out some nuts. Still too much. Out of the parcel there disappears something tightly 
wrapped in foil. Most likely biscuits. Too heavy. On the scale a third time - almost right only a little needs to be still taken out. Finally! The scale points ideally to the required weight. The last knot can be tied and the parcel addressed - the such and such jail, prisoner Ales Bialacki. Ready. Whether the parcel will in fact reach the addressee is a completely different matter.

What is this scene about? About love? Absolutely - it is enough to focus on the face of the woman, on her difficulties and determination. Or humiliation? Of course it is - it is only necessary to add the mocking glances of passers-by and a close-up of the postal worker when she's chewing gum and states "too heavy", "I said it is too heavy!" "Well make up your mind and decide how much!" Is it about hope? Certainly. It is only necessary to capture that look, when the addressed parcel lands on a pile of others and the beautiful woman is still following it with her gaze. And smiles. There are many more still meanings possible here and, therefore, means of building the scene with the parcel. The person that finds themselves in the film is not dependent on the female protagonist or the person holding the camera and who manages to capture or to miss this that or the other. It all depends on the director. It is he who chooses from the material he sees in this scene - there at the very moment - and what he considers to be the most important. This does not have to be a truth that is 'absolute. The spiky postal worker can have her speech cut out altogether and there remains a bored woman in a uniform. It is possible not to show the stairs. So a woman bought some biscuits and now they do not fit into the parcel, a pity. It is possible not to show the addressing of the parcel and not to say that the parcel is meant for a jail - let that be a secret.

At times, it is the case that we see something and it appears to be important but we do not know why. We do not have to know. Unless of course, we are a documentary film maker. Then we do. We do not always know for a particular reason - but we do all the same, for this is the nature of our profession. So as to document and filter what the world outside lays at our feet. And at times even to shape that world (a little).

The director of a documentary film filters the world outside through their innards. There is no obligation to anything beyond honesty in respect to the protagonist and to themselves. The audience is often led on a merry dance as it were - and even enjoys this. And as far as the 'objective truth', 'need of the moment' and suchlike are concerned, the director may well have them deeply you know where. The filmmaker is, in the one person, the helm, sailor and ship. The audience therefore truly senses whether the director is playing fair. If not, then we reach for the remote or leave the cinema, because tickets for documentary films are cheap and it's no great loss...

Since the film maker has such a great responsibility for their work, can the art of the direction of documentaries be taught? Is not another person - in addition a director as well - an unwelcome figure, 
perhaps even a pest, if they come between the artist and the work and attempt to have their say and to give advice? Honestly - I don't know but do not exclude such a possibility.

I received an invitation to workshops with Belarusian directors so as to work on their film projects. I've found the most rapport with Aleh Dashkevich, an intelligent introvert, sensitive and sympathetic, who wished to make the film The Speech (Przemowa) about Ales Bialacki - his archives, matters that were highly important. The project had somewhat of a feel similar to a television report; there is no suggestion that it had the features of a film. Aleh had an ace up his sleeve: he is a friend of the family and knows Natalia Pinchuk (Bialacki's wife) very well. She - who doesn't like the media, always stays well back in the background - in his presence she is perfectly natural. To say the very obvious, she is simply herself.

I don't know how it happened, but Aleh decided to drop what for him was incredibly important at the beginning: Bialacki's speech in jail (clever and dramatic at that). All the press and film fragments of Bialacki collected over the years - Aleh removed all of this from his head. And he looked at his protagonist from the point of view of the woman closest to him - and saw a fantastic subject. In that petite, beautiful blonde. I recall how he came to Poznan and showed me the recorded materials at Natasha's home. A woman sitting at the table. She is drinking tea. Opposite her a chair, pushed away a little - it is enough to bring it closer, take a seat and be together. But in the apartment silence reigns, only the ticking of the clock can be heard. After a while it is clear that this chair shall remain empty. The telephone rings. Natasha jumps up, seizes the receiver, talks, all the time placing it first to one year then the next. The long fingers either wind themselves around the telephone cord or will make hurried notes from the discussion. Smiles. Questions break off. Emotions are bubbling over. Beep... Beep... End of talk.

The woman replaces the receiver, but is still the happy Natasha in love. She cannot come to herself. This lasts a good 40 or so seconds. Then a glance at the empty chair. The woman returns to her tea. She is still looking through her notes. She speaks to the director whom she has forgotten: "Will ring in a week - if he can manage..." A smile. A glance towards the window. The face ever so slowly becomes grey, as if the sun was setting. But the sun has long gone. Natasha recedes into the background. Time, it would appear, again is dragging horribly. There is nothing. Tick... Tock... Tick... Tock... Silence.

We watched this scene in a Poznan cafe and I couldn't hide the fact I was moved. This unedited, raw material was a veritable thunderbolt. It was about a strong, fascinating woman, but after all also about Bialacki. And this was more, more interesting than the fragments of his speeches. This was a fantastic document and, at the same time, a film of the truest kind. It was simply a picture that carries authentic emotions. Then Aleh decided to forget about the film The Speech and 
make From call to call - a simple film about love that lasts despite the confines of a jail.

I remember that at the beginning he was still worried that the microphone had stopped functioning and that nothing that Bialacki is saying could be heard. And I recall how he completely stopped talking about this when he noticed that Natasha was enough for them both that the simpler, the plainer, the better.

Can another director be helpful so as to find a film that, after all, is only in one head? I think that at times yes. It provides an opportunity to look at the material anew, with a certain distance. When Aleh showed me the first recorded telephone conversation between Natasha and her husband, he attained something that can be lacking for most directors after months of arduous editing - freshness. Aleh had the opportunity to see my reactions and recall his own. The fresh ones, not the enth viewing of material - only the first. This is simply a treasure for an artist. It is not possible to keep back one's own feelings. That is why another person is helpful to a director - as a mirror.

And also as a nag - someone who says "here I can't understand what's happening" or "this is boring". And there is no need at all to agree, but one can have a look to see whether something in this scene can be tweaked, added to, or the context changed. And of course it serves as a type of litmus paper so as to check the balance of emotions, at any rate in the first audience - for even a fellow professional is above all, a part of the audience.

So, yes, it appears that another director at times can be helpful. Certainly in my case. The meeting with Aleh and Natasha proved to be a wonderful time. One of those meetings that changes us. I am very grateful to them. And shall always remember the image of the fingers that have to take some nuts out of a heavy parcel. A little more still, just a tad. 

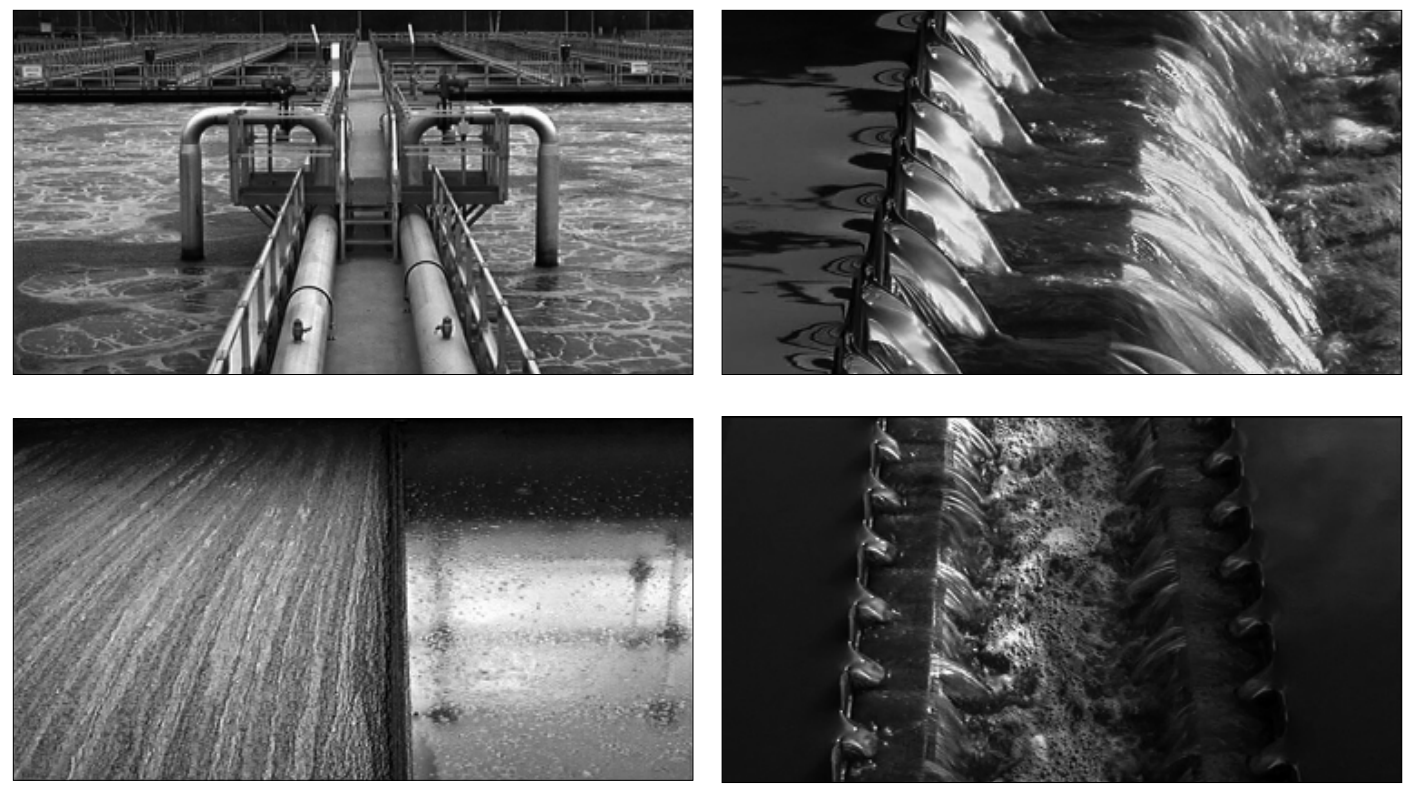

Treatment Plant, dir. Jenifer Malmqvist (Łódź from Dawn till Dusk), prod. Polish National Film School in Lodz, 2007 